\title{
DOM ADRIANO ENTRE OS LIBERTADORES DA AMÉRICA
}

\author{
Adriana Bastos Kronemberger \\ Pontifícia Universidade Católica de São Paulo
}

\begin{abstract}
Resumo: Este artigo é parte da minha tese de mestrado, que defenderei ainda este ano na Pontifícia Universidade Católica de São Paulo - PUC SP. Na minha pesquisa, analiso os discursos políticos realizados por Adriano Hypólito, sacerdote franciscano, seguidor da Teologia da Libertação, que foi bispo na cidade de Nova Iguaçu durante os anos da ditadura civil e militar no Brasil. Por seu ponto de vista ideológico, o bispo foi sequestrado e espancado na segunda metade da década de 1970. As principais fontes deste trabalho são os discursos publicados pelo jornal semanal diocesano de Nova Iguaçu, denominado de $A$ Folha, uma entrevista que Dom Adriano Hypólito deu à Revista de Cultura Vozes em 1988, uma entrevista também dada por ele à Revista Playboy em 1978, bem como o documentário: Nova Iguaçu, a cidade dos meus olhos (2003). A metodologia utilizada aqui será a leitura das fontes em diálogo com obras que se referem às transformações na Igreja Católica, às formações sociais, espaciais e ideológicas do Brasil e da Baixada Fluminense: A Igreja na Sociedade Liberal e no Mundo Moderno (1976), de Roger Aubert et al; Os bispos católicos e a ditadura Militar no Brasil - A visão da espionagem (2014), de Paulo César Gomes; as notas biográficas sobre Dom Adriano produzidas por Carlos Lacerda de Meneses (2010); A Igreja do Brasil: de João XXIII a João Paulo II, de Medellín a Santo Domingo (1993), de José Oscar Beozzo; Michael Lowy em : A Teologia da Libertação: Leonardo Boff e Frei Betto (2008) e Walter Benjamin: Aviso de Incêndio - Uma leitura das teses "Sobre o conceito de história" (2005); Alexandre de Souza Gomes em Religião e política: construção da memória de Dom Adriano (2012); Alexandre de Souza Gomes em Religião e política: construção da memória de Dom Adriano (2012) e Leonardo Boff em Jesus Cristo libertador (1985). Desta perspectiva, será feita uma análise do trabalho pastoral da Igreja de Nova I guaçu na figura do bispo Adriano Hypólito na década de 1970. A justificativa para este trabalho é uma tentativa de resgatar um modelo de Igreja que, em certo momento histórico, propôs uma religiosidade socialmente ativa. A discussão proposta neste trabalho também pode ser considerada no contexto da educação fundamental, uma vez que é cada vez mais difícil o diálogo aberto sobre as diversas influências religiosas que existem no Brasil. Isso ocorre porque vivemos um momento de extrema intolerância, situação geradora e perpetuadora dos preconceitos.
\end{abstract}

Palavras-chave: Hypólito. Resistência. Ditadura. Religião. Teologia. VIII

\footnotetext{
${ }^{1}$ Mestranda em História Social. Bolsista CNPq.
}

\section{Blucher}


Dom Adriano among the America Liberators

Abstract: This article is part of my master's thesis, that I will defend later this year at the Pontifical Catholic University of São Paulo - PUC SP. In my research, I analyze the political discourses undertaken by Adriano Hypólito, a franciscan priest, follower of the Liberation Theology, who served as a bishop in Nova Iguaçu city during the years of the civil and military dictatorship in Brazil. Because of his ideological point of view, the bishop was kidnapped and beaten in the second half of the 1970s. The primary sources of this work are issues of the diocesan weekly newspaper, the so called Nova Iguaçu, A Folha, an interview that Adriano Hypólito gave to the Revista de Cultura, Vozes in 1988, an interview also given by him to Revista Playboy in 1978, as well as the documentary Nova Iguaçu, the city of my eyes (2003). The methodology used here, will be the reading of the sources in dialogue with works that refer to the transformations in the Catholic Church, to the social, spacial and ideological formations of Brazil and the Baixada Fluminense: A Igreja na Sociedade Liberal e no Mundo Moderno (1976), by Roger Aubert at al; Os bispos católicos e a ditadura Militar no Brasil - A visão da espionagem (2014), by Paulo César Gomes; the biographical notes on Dom Adriano produced by Carlos Lacerda de Meneses (2010); A Igreja do Brasil: de João XXIII a João Paulo II, de Medellín a Santo Domingo (1993), by José Oscar Beozzo; Michael Lowy in A Teologia da Libertação: Leonardo Boff e Frei Betto (2008); Walter Benjamin: Aviso de Incêndio - Uma leitura das teses "Sobre o conceito de história" (2005); Alexandre de Souza Gomes in Religião e política: construção da memória de Dom Adriano (2012); Alexandre de Souza Gomes in Religião e política: construção da memória de Dom Adriano (2012) and Leonardo Boff in Jesus Cristo libertador (1985). From this perspective, an analysis will be made of the pastoral work of the Church of Nova Iguaçu in the figure of Bishop Adriano Hypólito during the 1970s. The justification for this work is an attempt to rescue a model of Church that, at a certain historical moment, proposed a socially active religiosity. The discussion proposed in this work can also be considered in the context of fundamental education, since it is increasingly difficult to propose an open dialogue about the diverse religious influences that exist in Brazil. This is because we live a moment of extreme intolerance to the different, a generative and perpetuating situation of prejudices.

Keywords: Epistemology. Quantum Physics. Reality. Philosophy of Science. Classical Physics. 
Durante a década de 1970, Dom Adriano Hypólito bispo da cidade de Nova Iguaçu ganhou destaque nacional ao empreender uma prática de luta política e assumir uma postura de crítica em relação à ditadura civil militar. Este bispo lutava por justiça social e pelos Direitos Humanos em uma região marcada pela brutalidade e pela desigualdade social. Neste artigo farei uma análise da formação ideológica de Dom Adriano e das transformações ocorridas na Igreja Católica que culminaram com as ações pastorais do bispo em Nova Iguaçu na década de 1970.

A minha fonte primária é o jornal diocesano de Nova Iguaçu denominado A Folha, onde constam artigos produzidos por Dom Adriano e/ou orientados por ele. Como fontes secundárias, utilizo uma entrevista concedida pelo bispo à Revista de Cultura Vozes, em 1981 e uma entrevista concedida à Revista Playboy em 1978. Tais documentos estão disponíveis na Cúria diocesana de Nova Iguaçu. Para lidar com as minhas fontes utilizo o método de leitura e análise dos discursos de Dom Adriano em diálogo com obras que se referenciam às formações social, espacial e ideológica do Brasil e da Baixada Fluminense, particularmente dialogando com os trabalhos referenciados no resumo deste trabalho.

Apesar de muito já se ter discutido sobre a posição da Igreja Católica durante os anos da ditadura civil militar no Brasil, acredito que este trabalho se justifica pela proposta de reflexão acerca do papel da religiosidade na sociedade brasileira, buscando rediscutir uma Igreja que se posicionou entre a coletividade e 0 individualismo, que foi socialmente ativa e buscou fortalecer os laços de comunidade.

\section{Dom Adriano e a Baixada Fluminense:}


De acordo com o historiador Antônio Lacerda de Meneses (2010), Dom Adriano Hypólito nasceu em Aracaju no ano de 1918 e recebeu o nome de Fernando Polito. Estudou no Seminário de Rio Negro, no Paraná, onde foi colega de Dom Paulo Evaristo Arns e no ano de 1937 vestiu 0 hábito dos franciscanos, passando a se chamar Adriano. Em 1962, frei Adriano participou do Concílio Vaticano II (1962 - 1965), quando foi indicado pelo o Papa João XXIII a bispo auxiliar da Arquidiocese de São Salvador da Bahia. Dom Adriano chegou a Nova Iguaçu no ano de 1966, nomeado pelo papa Paulo VI. Ao assumir a diocese dessa cidade passou a desenvolver um trabalho voltado aos problemas sociais da região, fato que o converteu em uma figura de grande importância regional e nacional.

Ao iniciar seus trabalhos em Nova Iguaçu se viu na Baixada Fluminense, uma região conflituosa que de acordo com Alessandra Siqueira Barreto, em seu trabalho Um Olhar Sobre a Baixada: Usos e representações sobre o poder local e seus atores (2004), hoje pode ser definida ou como uma região de planícies que está entre o litoral e a Serra do Mar. Segundo dados do IBGE, no ano de 2000 a população da região passava de três milhões. Os municípios que compõem esta região são: Belford Roxo, Duque de Caxias, Guapimirim, Itaguai, Japeri, Magé, Mangaratiba, Mesquita, Nilópolis, Paracambi, Queimados, São João de Meriti, Seropédica e Nova Iguaçu.

Nova Iguaçu fica na região Metropolitana do Rio de Janeiro a 28 km da capital do estado. Em 2012 sua população era estimada em 801746 habitantes de acordo com Instituto Brasileiro de Geografia e Estatística. Seu nome vem de "Iguaçu", um termo tupi cujo significado é "rio grande" ou "água grande", os indígenas jacutingas eram os naturais da região. De acordo com 0 
documentário: Nova Iguaçu, a cidade dos meus olhos ${ }^{2}$ (2003), na época da colonização a economia da região girava em torno da agricultura da cana de açúcar. Até o início do século XIX, Piedade do Iguassu era o principal povoado da região, mas entrou em decadência por várias razões, entre elas a criação das estradas de ferro; epidemias de cólera, varíola e malária e a abolição dos escravos. Após as epidemias que ocorreram na região a população da Vila transferiu-se para o Arraial de Maxambomba, que em $1^{\circ}$ de maio de 1891 também recebeu a sede do município. À época do Segundo Império chegaram as locomotivas a vapor (em 1858, a Estrada de Ferro Dom Pedro II, atual Estrada de Ferro Central do Brasil foi inaugurada), marcando a entrada da modernização na cidade. A Vila de Maxambomba recebeu o nome de "Nova Iguassu" em 09 de novembro de 1916.

Ainda segundo o documentário: Nova Iguaçu, a cidade dos meus olhos (2003), por volta de 1891, Nova Iguaçu passou a produzir e a exportar laranjas com o auge dessas atividades entre os anos 1930 e 1950. Porém durante a Segunda Guerra Mundial houve interrupção do transporte marítimo, impedindo a exportação das laranjas, o que deu origem à chamada "crise da laranja", quando a cidade entrou em um processo de industrialização, beneficiado pela facilidade de escoamento da produção através das rodovias que cortam o município e pela grande oferta de mão de obra barata aumentada pelo processo de migração. Situação que agravará consideravelmente os problemas sociais da cidade nos anos de 1970. Nas palavras de Dom Adriano:

Esta região do Brasil recebe pessoas vindas de várias regiões, e essa gente leva um tempo para se fixar em um novo lugar, ou não conseguem, uma vez que se

\footnotetext{
${ }^{2}$ Nova Iguaçu, a cidade dos meus olhos. FAUISTINI, MARCUS. Documentário com a participação dos historiadores Antônio Lacerda e Ney Alberto, MP3 Lyrics, 18 min. 2003. Publicado no https://www.youtube.com/watch?v=dBQkFSAvHJo - Em 23 de maio de 2013.
} 
mantêm presos a modos de vida bastante diferentes". "De fato, uma grande parte da população, vinda de fora, isto é: do Nordeste, do Espírito Santo, de Minas Gerais e do Norte Fluminense, aqui ainda não encontrou a possibilidade de se enraizar. Quase todos eram pequenos lavradores que usavam como instrumento principal na lavoura a velhíssima enxada. Outros eram agregados de grandes latifúndios. Aqui têm de mudar de trabalho sem poder mudar de mentalidade." (A FOLHA, 1972, p. 1).

Nas palavras acima o bispo levanta a questão da chegada de novos moradores à região iniciada entre os anos de 1950 e 1960, situação que se revelará determinante na organização dos movimentos urbanos de Nova Iguaçu nas décadas posteriores, pois diante das dificuldades impostas pela nova realidade social e material dos novos e antigos trabalhadores, novas emergências surgirão com força impulsionando uma nova organização social.

No início de suas atividades em Nova Iguaçu Dom Adriano concedia entrevistas para vários jornais e revistas falando da realidade conflituosa da região. Contudo, seu instrumento mais ativo de denúncia das mazelas sociais e do descaso público era o jornal semanal de sua diocese, denominado de $A$ Folha, que surge aqui como um documento que instrumentaliza a minha compreensão histórica acerca da figura política de Dom Adriano.

De acordo com o próprio bispo, A Folha surgiu em 11 de junho de 1972 na forma de semanário litúrgico e com a intenção de ser um instrumento de comunicação interna da Diocese de Nova Iguaçu, mas aos poucos extrapolou os muros das Igrejas Católicas daquela cidade, assumindo uma postura de conscientização política a partir das linhas pastorais da Teologia da Libertação. Nas palavras de Dom Adriano (1993): 
Inicialmente A Folha queria ser um instrumento de comunicação interna da Diocese de Nova Iguaçu. Aos poucos foi assumindo uma dimensão pastoral conscientizadora a partir da Liturgia e das linhas pastorais de nossa diocese. Baseando-se na Liturgia do domingo e na doutrina do Vaticano II, os artigos procuraram exprimir os dois grandes mandamentos nos quais se resumem a lei e os profetas: amor a Deus e Amor aos irmãos e irmãs. Nunca faltou em $A$ Folha a dimensão social da Boa Nova de Libertação total (...) os artigos procuravam sacudir a consciência dos católicos e movê-las a assumir a causa dos irmãos pequenos com os quais Cristo se identifica (...) Lembrando-nos da integralidade da pessoa humana em sua dignidade total de corpo e de alma, gostaríamos de atender como Jesus às necessidades materiais prementes como são: trabalho, educação, saúde, salário, participação no processo social, direitos humanos, direitos da cidadania etc. (A FOLHA, Ano 20, No 1143, 1993).

Na citação acima o bispo reconhece a importância que o jornal diocesano $A$ Folha teve para a realização de sua obra em Nova Iguaçu, mas defende que a intenção inicial de $A$ Folha era de se restringir ao universo da própria diocese. Todavia, ao assumir uma dimensão "conscientizadora", A Folha alcançou uma dimensão social que fez desse jornal diocesano um objeto de contínua vigilância dos órgãos de informação da ditadura civil militar. Isto porque em $A$ Folha ficava evidenciado que o trabalho de Dom Adriano em Nova Iguaçu era marcado por um forte posicionamento ao lado do povo pobre da região, sempre buscando o diálogo, mas com muita resistência aos desmandos do poder político e das elites locais.

\section{Caminhando para a Libertação:}

Em A Folha o bispo escrevia sobre a Baixada Fluminense, sobre o Brasil, sobre o mundo e desenvolvia suas ideias de trabalhar uma Igreja com clara opção pelos menos favorecidos: 
Para mim, uma coisa essencial nesta caminhada da Igreja no Brasil (Também na América Latina, também no mundo de hoje) é a consciência de que a Igreja tem de si mesma, a imagem que ela representa e vive na sua vida interior e na sua prática pastoral. 0 Concílio Vaticano II captou lucidamente a doutrina secular e as experiências mais recentes. (...) Esta é a Igreja do Povo da nova aliança, é o Povo messiânico, é o Povo que realiza as promessas dos pais, é a realização concreta do plano de amor do Pai. (HYPÓLITO, 1981, p. 60)

Em uma breve análise dessas palavras de Dom Adriano, percebe-se que ele se posicionava de forma consciente a respeito da ideia de Igreja em que ele acreditava e pela qual lutava. Contudo, este posicionamento do bispo de Nova Iguaçu estava em alinhamento com 0 posicionamento defendido por setores da Igreja Católica nos anos de 1970, neste período havia um movimento católico que se espalhou pela América Latina e ficou conhecido como Teologia da Libertação. Tal movimento religioso surgiu como resultado de decisões tomadas no Concílio Vaticano II (1962), que propôs transformações no interior da Igreja, essas transformações conduziriam a doutrina católica para um engajamento político de forte expressão na América Latina na década de 1970. A partir de então, a Igreja Católica começou a pensar mais nas questões sociais.

Contudo, Gomes (2014) nos diz que essas modificações do pensamento católico não ocorreram soltas no tempo, surgiram como resultado da necessidade da Igreja se adequar às novas realidades que surgiram desde a expansão das ideias liberais inseridas na sociedade moderna. As ideias do Iluminismo e da Revolução Francesa fizeram crescer um sentimento negativo em relação ao clero. As revoluções liberais do século XIX espalharam pelo mundo o individualismo dos liberais e o materialismo dos socialistas e neste mesmo século, os movimentos operários e o comunismo cresciam. Então a Igreja teve de encontrar alternativas para lidar com esses novos "inimigos", 
elaborando um discurso disciplinador em relação ao socialismo e também ao liberalismo. Dessa forma, a Igreja reforçou o paternalismo da ação social com relação aos pobres, onde o operariado seria 0 recebedor de concessões dos patrões e não o protagonista nas conquistas de direitos. (GOMES, 2014).

Esta situação se inverterá nos anos 1970, particularmente nos trabalhos pastorais de Dom Adriano em Nova Iguaçu: "esta Igreja, que é uma instituição, certo, é antes de tudo um ministério (..) um serviço (...) que veio para servir e não para ser servido (...) Também na realização de sua opção pelos pobres, a Igreja tem de estar bem cônscia de que veio para servir. Senão, assumirá uma posição de paternalismo (...) que vai perturbar e mesmo estragar o crescimento do Povo de Deus". (HYPÓLITO, 1981, p. 60). 0 bispo afirmava que não cabia à Igreja uma postura paternalista em relação ao povo, mas sim uma posição de servidora, de instrumento para a libertação do povo das amarras da opressão. Este posicionamento era comum entre os adeptos da Teologia da Libertação, que se posicionavam ao lado dos "oprimidos" e estavam dispostos a construir uma Igreja mais próxima do povo e mais democrática, reconhecendo as especificidades de um povo muito heterogêneo na América Latina e adequando seus discursos às necessidades materiais mais imediatas e mais próximas das comunidades regionais nas quais estavam inseridos.

\section{Libertadores da América:}

Como já mencionado, as transformações na doutrina católica que deram origem à Teologia da Libertação na América Latina foram se dando de acordo com as ressignificações sociais ocorridas a partir da sociedade moderna, passando pela difusão das novas correntes de 
pensamento do século XIX que fortaleceram o individualismo e as ideias comunistas, fazendo com que a Igreja Católica reagisse. Aubert at al (1976) nos dizem que no século XX, mas especificamente após a Segunda Guerra Mundial, o clero da América Latina dedicava crescente atenção à situação das massas e se preocupava cada vez mais com a justiça social, isto porque se os líderes católicos falhassem em ouvir as massas, as mesmas seriam arrebatadas pelos então inimigos da Igreja: os marxistas.

Nessas condições ocorreu o Concílio Vaticano II (1962 - 1965), que foi um encontro ecumênico convocado pelo papa João XXIII, quando e onde a Igreja Católica apresentou renovações institucionais expressivas que se difundiram na América Latina a partir da Conferência Episcopal de Medellín, Colômbia (1968), quando foi repensado o papel da Igreja na região e foi decidida a opção preferencial da Igreja pelos pobres, dando origem ao movimento católico denominado de Teologia da Libertação. Assim, os seguidores da Teologia da Libertação durante os anos de 1970 reproduziam discursos orientados para a defesa dos pobres e na busca pela justiça e pela paz social. Dom Adriano Hypólito era um árduo defensor dessas ideias:

A Igreja tem de ser uma Igreja do Povo e não uma Igreja das elites, tem de ser uma Igreja dos pobres, dos fracos e dos humildes, não uma Igreja dos ricos, dos fortes, dos poderosos. De tal sorte que na vida concreta da Igreja, tem de se repetir (...) uma espécie de exigência ontológica, aquelas tensões que havia entre Jesus Cristo e as classes dominantes. E se me perguntassem: "Então a Igreja não veio para salvar a todos como Jesus Cristo, também aos ricos?" eu diria: "Sim, na medida em que os ricos se despojam de suas riquezas e grandezas e se fazem Povo, se fazem pobres, se fazem crianças". (HYPÓLITO, 1981, p. 60). (Grifos do autor) 
Nas palavras do bispo há uma clara referência a sua opção por uma Igreja identificada com os mais pobres e também apontam tensões nas relações existentes entre a Igreja e as elites econômicas e autoritárias. Dentro dessa ideia não posso perder de vista a reação dos governos autoritários da América Latina ao trabalho dos defensores desse modelo de Igreja. Entre as décadas de 1960, 1970 e 1980 o cenário mundial estava bem complicado, particularmente por causa dos ideários rivais da Guerra Fria que dividiam o mundo entre socialistas e capitalistas. Na América Latina depois da Revolução Cubana (1959), forças conservadoras aliadas a alguns setores da sociedade civil apoiaram a instituição de governos militares e a ascensão de ditaduras. Sobre isso Dom Adriano refletiu: "Nas circunstâncias políticas de nossos países latino-americanos é muitas vezes a Igreja a única voz ou pelo menos a voz mais forte de defesa dos direitos humanos, de defesa do Povo, de defesa da justiça social. Daí os conflitos e atritos com os regimes autocráticos e ditatoriais. Cabe assim à Igreja um importante papel conscientizador de nossos Povos latinoamericanos. (HYPÓLITO, 1981, p. 64)".

Para melhor compreender a dificuldade daqueles religiosos que assumiram a opção pastoral da Teologia da Libertação na América Latina nos anos de 1970, cabe saber que depois de encerrado o Concílio Vaticano II (1965), o episcopado latino-americano demonstrou disposição em assumir uma posição mais autônoma em relação a Roma. Além disso, segundo Beozzo (1993), a partir da Conferência Episcopal de Medellín (1968), aprofundou-se a noção de justiça e paz ligadas aos problemas de dependência econômica, assim o pobre foi colocado no centro da reflexão dos problemas do continente. Nesse período, um grupo de intelectuais católicos chamados de nova esquerda e que se dizia humanista, se preocupava em efetuar mudanças radicais na sociedade, 
mesmo que para isso tivessem de se associar a grupos marxistas. Situação que não agradava nem aos governos ditatoriais alinhados com os Estados Unidos, nem à ala mais conservadora da Igreja, que via no comunismo, um antigo inimigo ateu.

Todavia, os adeptos das transformações mais radicais seguiam com sua teologia revolucionária. Michael Lowy em seu trabalho A Teologia da Libertação: Leonardo Boff e Frei Betto (2008), evidencia o papel do povo pobre como ideia central da Teologia da Libertação, tal ideia pode ser resumida na frase: "opção preferencial pelos pobres". No entanto, para Lowy (2008), a Teologia da Libertação ia além da propagação do evangelho de Cristo entre os pobres, estava relacionada com a transformaç̧ão das condições de vida das pessoas exploradas e das relações entre a Igreja e seu povo. Segundo Lowy (2008):

Uma implacável acusação moral e social contra o capitalismo como sistema injusto e iníquo, como forma de pecado estrutural. 0 uso do instrumento marxista para compreender as causas da pobreza, as contradições do capitalismo e as formas da luta de classes. A opção preferencial a favor dos pobres e a solidariedade com sua luta de emancipação social. 0 desenvolvimento de comunidades cristãs de base entre os pobres como a nova forma da Igreja e como alternativa ao modo de vida individualista imposto pelo sistema capitalista. (...) 0 consumismo, a riqueza, o poder, a segurança nacional, o Estado, os exércitos; em poucas palavras, "a civilização cristã ocidental". (LOWY, Adital, 2008)

Lowy (2008) aponta que a aproximação ideológica da Teologia da Libertação com 0 comunismo estava clara e que nos escritos de importantes representantes brasileiro da Teologia da Libertação, aparecem a partir dos anos de 1970 conceitos e temas marxistas. Contudo, a proximidade ideológica do cristianismo com o marxismo não seria nova para a história. Destaco 
uma análise da tese I de Walter Benjamin, que consta do livro Walter Benjamin: Aviso de Incêndio - Uma leitura das teses "Sobre o conceito de história", de Michael Lowy (2005). Lowy interpreta as alegorias utilizadas pelo filósofo alemão Walter Benjamin, 0 autômato e 0 anão. De acordo com 0 autor, para ganhar a partida o materialismo histórico precisa da ajuda da teologia, que seria um anão escondido em uma máquina. Este, por sua vez, só poderia agir às escondidas, de forma a complementar o trabalho do materialismo histórico. Neste caso, a teologia estaria a serviço da luta dos oprimidos. Na perspectiva analítica de Lowy (2005), aos olhos de Benjamin a teologia deve servir para restabelecer a força explosiva, messiânica, revolucionária do materialismo histórico, para que enfim o desenvolvimento das forças produtivas leve à crise final do capitalismo.

\section{A Teologia da Libertação na ditadura civil militar no Brasil:}

Historicamente o catolicismo sempre marcou presença em momentos conflituosos da formação da sociedade brasileira, na maioria das vezes legitimou a ordem estabelecida. Em 1964 não foi diferente, a Igreja Católica esteve ao lado das elites e das Forças Armadas apoiando o golpe civil militar no Brasil. Contudo, o apoio da Igreja Católica ao golpe diminuiu com o tempo. No decorrer da política dos militares alguns setores da Igreja, inspirados pela Teologia da Libertação, passaram a criticar o regime autoritário, a defender os Direitos Humanos e a trabalhar nas comunidades uma pastoral voltada para a conscientização política e para as necessidades materiais do povo pobre. 
Tal situação transformou a CNBB (Conferência Nacional dos Bispos do Brasil), alvo dos órgãos de informação da ditadura. Para os militares havia dentro da Igreja Católica uma ala muita próxima dos ideais comunistas, no entanto, Dom Adriano (1981), assim como outros padres "progressistas", negava tal aproximação e dava outra interpretação para o trabalho da Igreja durante a ditadura: "Tais interpretações, totalmente deformadoras da realidade, podemos leva-las à conta de uma psicose social que se apoderou das elites do poder, talvez como fruto de uma incompreensão para o mais profundo mistério da Igreja, talvez como permanência inconsciente do conceito de uma Igreja contestadora do governo, talvez mesmo como mecanismo de defesa. Uma Igreja-Povo de Deus, que não é somente clero e hierarquia (...)" (HYPÓLITO, 1981, p. 56).

\section{O bispo comunista:}

"Mitte, Domine, operarios" (Enviai, Senhor, operários). ${ }^{3}$

Apesar de muitos religiosos negarem a aproximação de setores da Igreja com 0 marxismo, as ações de alguns clérigos deixavam os militares nervosos e cada vez mais convencidos da presença comunista na Igreja. Diante disso, as Forças Armadas redobraram a vigilância sobre a Igreja e intensificaram os ataques a militantes católicos. Dom Adriano Hypólito estava entre os religiosos vigiados e perseguidos. Isto porque desde 1972, Dom Adriano usava o semanário litúrgico $A$ Folha como um instrumento de formação de uma consciência política e de denúncias

\footnotetext{
${ }^{3}$ Inscrição do brasão de posse de Dom Adriano como bispo.
} 
contra várias situações que ele considerava injustas. Tal postura incomodava, tanto às elites locais quanto aos órgãos de informação da ditadura civil e militar. Em sua entrevista à Revista de Cultura Vozes (1981), o bispo falou sobre esse período:

Lembro-me agora de alguns acontecimentos. Além do sequestro, em 22 de setembro de 1976, houve a falsificação de $A$ Folha (...) com milhares de números falsos distribuídos (...) pelo Brasil afora; panfletos caluniosos contra 0 bispo (...) em março de 1978, sou seguido secretamente em meus movimentos dentro da diocese e nas visitas que fiz a outros bispos (...) acompanhado até mesmo de helicóptero, quando fui fazer uma conferência para o clero de Volta Redonda, no centro de Formação de Arrozal; ameaças de novo sequestro e de castigo exemplar (...) (D. ADRIANO, 1981, p. 68)

Ao encontro das palavras do bispo segue vasta documentação arquivada na diocese de Nova Iguaçu que aponta que entre os anos de 1976 e 1979 o bispo foi bastante perseguido, vigiado e ameaçado. Como visto na citação, seus movimentos interessavam muito ao poder constituído. Além disso, era comum que os políticos da região promovessem reuniões com militares para discutir os textos publicados pelo semanário litúrgico A Folha. Assim, em 22 de setembro de 1976, Dom Adriano foi sequestrado e espancado. Sobre esse episódio o bispo falou em entrevista à Revista Playboy:

Eram seis homens e estavam armados com revólveres. Eles enfiaram um capuz na minha cabeça, me obrigaram a entrar num automóvel, arrancaram minhas roupas e passaram a chutar e pisar meu corpo. Eu estava certo de que iam me matar. Refleti sobre os motivos que levariam aqueles homens a me tirar a vida e conclui que aquilo tudo só podia ser consequência de minha atuação. A 
consciência disso me acalmou, preparei-me para morrer, enquanto meus sequestradores prosseguiam me submetendo a toda sorte de humilhações. Depois de esguicharem um spray de tinta vermelha sobre meu corpo, me abandonaram algemado e nu, numa rua escura de Jacarepaguá. Mas antes me advertiram que da próxima vez eu não escaparia com vida. (DANTAS, 1978).

Muitas pessoas ligadas a Dom Adriano acreditavam que tal violência havia sido uma resposta ao trabalho dele e, conforme as palavras acima, o próprio bispo tinha essa consciência. Mas, apesar de ser notícia nacional, este episódio foi marcado por um enorme silencio em relação a sua investigação e autoria. No entanto o bispo tinha suas desconfianças. Em entrevista à Revista de Cultura Vozes em 1981, o bispo afirmou que seu sequestro provavelmente teria na Vila Militar do Rio de Janeiro a sua origem, orientação e cobertura. (MEU, 1981, p. 67). Com este mesmo posicionamento 0 jornal Movimento, de 09 de dezembro de 1979, afirmou militares liderados por José Ribamar Zamith foram os responsáveis pelo sequestro do bispo. Ainda de acordo com este jornal, o Exército sabia da autoria do sequestro, mas manteve a informação secreta. Contudo, no relatório final da Comissão da Verdade do Rio (CEV-Rio) $(2015)^{4}$, consta a seguinte afirmação:

(Acréscimo CEV-Rio) José Ribamar Zamith Capitão Comandante da $1^{\text {a }}$ Companhia de Polícia do Exército. Participou de sessões de tortura nas instalações do Pelotão de Investigações Criminais (PIC), posteriormente Destacamento de Operações de Informações - Centro de Operações de Defesa Interna (DOI-CODI) do Rio de Janeiro. É também suspeito de ter participado do sequestro do bispo dom Adriano Hipólito, em 1976, e do atentado à bomba no Riocentro, em 1981. (Rio de Janeiro - CEV-Rio- Comissão da Verdade do Rio de Janeiro, 2015, p. 414).

\footnotetext{
${ }^{4}$ Parte V: Autoria das graves violações de direitos humanos, Capítulo 20 - Autores das Graves violações de Direitos Humanos segundo a CEV-Rio,
} 
Dom Adriano morreu em 1996 sem ver essas informações virem à tona, pois foram necessários bons longos anos para que as investigações fossem reanalisadas pela Comissão da Verdade do Rio de Janeiro e mesmo assim as coisas não andaram do jeito que o bispo esperava, pois além de figurar apenas como suspeito do seu sequestro no relatório da CEV - Rio (2015), José Ribamar Zamith morreu em 2014.

\section{Considerações finais:}

Em uma análise da década de 1970 encontramos na cidade de Nova Iguaçu um bispo defendendo e pondo em prática os ensinamentos da Teologia da Libertação: Dom Adriano Hypólito. Este bispo travou lutas conscientes em territórios minados, tentou manter-se fiel às suas convicções, apesar de ter de remediar seus discursos algumas vezes, por questões de sobrevivência intelectual e até mesmo física. Na luta por justiça social e pelos direitos humanos ele esteve em conformidade com a luta da própria Igreja, mas algumas vezes extrapolou suas determinações sendo contundente em suas posições políticas e nas críticas em relação à ditadura civil e militar. Assim como a Teologia da Libertação foi resultado de várias modificações ocorridas no interior da Igreja Católica, o trabalho de Dom Adriano foi se alterando em algumas particularidades conforme ia se modificando o cenário político no Brasil e na Baixada Fluminense, mas nada de grande relevância capaz de alterar seu compromisso fundamental com os ensinamentos de Medelín (1968). 
Dessa forma, é possível vislumbrar através dos escritos de Dom Adriano, que nos anos violentos da ditadura civil militar no Brasil, a Igreja Católica inverteu seu papel de legitimadora da ordem estabelecida e passou a empreender uma transformação das práticas católicas, defendendo um cristianismo que ia contra a aceitação imóvel das injustiças sociais. Talvez naquele momento, em Nova Iguaçu, a religião tenha ensejado ser libertadora, agindo para uma transformação social.

\section{REFERÊNCIAS BIBLIOGRÁFICAS:}

ASSIS, João Marcus Figueiredo. A Diocese de Nova Iguaçu frente à Chacina da Baixada Fluminense: memória e identidade. Revista Horizonte, Belo Horizonte, V. 7, n. 13, p. 69-84, dezembro de 2008. AUBERT, Roger. at al. Nova História da Igreja - A Igreja na sociedade Liberal e no mundo moderno. Cap. V. Tomo II. Editora Vozes, Petrópolis, RJ, 1976.

BARRETO, Alessandra Siqueira. Um Olhar Sobre a Baixada: Usos e representações sobre o poder local e seus atores. Campos - Revista de Antropologia Social Campos, v. 5, n. 2, p 45 - 64, Curitiba. 2004.

BEOZZO, José Oscar. A Igreja do Brasil: de João XXIII a João Paulo II, de Medellín a Santo Domingo. Petrópolis, Editora Vozes, 1993.

BOFF, Leonardo. Jesus Cristo Libertador. Editora Vozes, Petrópolis, RJ, 1985.

CORRÊA, Elisa e MACEDO, Marcelo Ernandez. Zé Pureza e a reforma agrária no Rio de Janeiro do pré-64. Revista Estudo Sociedade e Agricultura. V. 15, n. 2, p. 368-392, Rio de Janeiro, 2007.

DE MENESES, Antônio Lacerda. Dom Adriano Hypólito - Apontamentos biográficos. 2010. Disponível em: http://domadrianohypolito.blogspot.com.br. Acesso em 30/09/2016. 
DO NASCIMENTO, Rafael Cerqueira. O Cristianismo da Libertação na I greja Católica de Nova Iguaçu: o jornal diocesano A Folha em oposição ao Regime Militar (1975-1981). Anais do XV Encontro Estadual de História "1964-2014: Memórias, Testemunhos e Estado", 11 a 14 de agosto de 2014, UFSC, Florianópolis.

GOMES, Alexander de Souza. Religião e política: construção da memória de Dom Adriano Hypólito. UERJ, 2012.

GOMES, Paulo César. Os bispos católicos e a ditadura militar brasileira - a Visão da espionagem. Editora Record, Rio de Janeiro / São Paulo, 2014.

LOWY, Michael. Walter Benjamin: Aviso de incêncdio - Uma leitura das teses "Sobre o conceito de história", São Paulo, Boitempo Editorial, 2005.

LOWY, Michael. Marxismo e Teologia da Libertação. Editora Cortez. São Paulo, 1991.

MAINWARING, Scott. A Igreja Católica e o movimento popular: Nova Iguaçu - 1974 - 85. In: A Igreja nas bases em tempo de transição (1974 - 1985)

MAINWARING, Scott. A Igreja e a Política no Brasil (1916-1985). São Paulo: Brasiliense, 1989.

KRISCHKE, Paulo, MAIWARING, Scott. (Org). L६PM Editores - CEDEC - Centro de estudos de cultura contemporânea, Porto Alegre- 1986.

RIBEIR0, Anderson Francisco. Do erótico ao pornográfico: A normalização das revistas Homem e Playboy (1975 -1978). Semana de História "Palavra e destino comum" UNESP/ Assis, 2004.

SPRÍCIGO, Sandra Helena. Uma apresentação da Revista de Cultura Vozes. Boletim de Pesquisa NELIC, v. 2, n. 3. Florianópolis, 1998.

\section{Site Consultado:}

http://domadriano.mitrani.org.br/vida.htm (acesso em 10/08/2010) 


\section{Fontes:}

\section{Imprensa católica:}

A FOLHA, ano I, No 4, 1972

A FOLHA, ano I, No 11, 1972

A FOLHA, ano I, No 12, 1972

A FOLHA, ano 20, No 1143, 1993

A FOLHA, ano 20, No 1114, 1993

A FOLHA, ano 20, No 1145, 1993

\section{Imprensa Geral:}

LOWY, Michael. A Teologia da Libertação: Leonardo Boff e Frei Betto. Adital, s/p, 2008.

O SEQUESTRADOR de D. Hypólito. Movimento, p. 12 e 13, 09/12/1979.

A VERDADE debaixo de sete palmos. Revista Carta CapitaL. Por Marcelo Auler. 16/05/2014.

Jornal Movimento - uma reportagem. Por Carlos Azevedo, Marina Amaral e Natalia Viana.

Jornal Movimento - Ato comemorativo dos 30 anos do jornal. Observatório da Imprensa, 25 de julho de 2005. Disponível em https://pt.wikipedia.org/wiki/Movimento. (acesso em 16 de julho de 2016)

Jornal 0 Pontual de 18/04/1975).

\section{Entrevistas:}

HYPÓLITO, Dom Adriano. Dom Adriano exclusivo: "Meu sequestro ainda é um mistério". Revista de Cultura Vozes. Ano 75, n.1, janeiro e fevereiro de 1981.

HYPÓLITO, Dom Adriano. A ira de Deus na terra da violência. Revista Playboy. Outubro De 1978. São Paulo. Entrevista concedida a Audálio Dantas 


\section{Documentário:}

FAUISTINI, MARCUS. Nova Iguaçu, a cidade dos meus olhos. Documentário com a participação dos historiadores Antônio Lacerda e Ney Alberto, MP3 Lyrics, 18 min. 2003. Publicado no https://www.youtube.com/watch?v=dBQkFSAvHJo - (acesso em 23 de maio de 2013)

\section{Outras fontes:}

- Rio de Janeiro - CEV-Rio- Comissão da Verdade do Rio de Janeiro, 2015, p. 414.

- Conferência Nacional dos Bispos do Brasil, temas de doutrina social da Igreja, caderno 1, Projeto Nacional de Evangelização queremos ver Jesus. $2^{\text {a }}$ edição. Paulinas - SP - 2006

- Centro de Pesquisa e Documentação de História Contemporânea do Brasil (CPDOC/FGV), biográfico, ABI-ACKEL, Ibrahim.

http://www.fgv.br/cpdoc/acervo/dicionarios/verbete-biografico/ibrahim-abi-ackel (acesso em 16 de julho de 2016). 